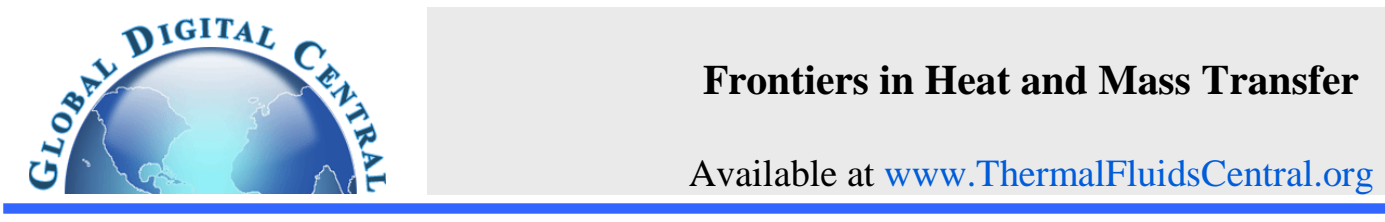

\title{
STUDY ON THE LIFETIME OF CATALYST IN CATALYTIC COMBUSTION FURNACE OF NATURAL GAS AND APPLICATIONS OF HEATING POTTERY
}

\author{
Shihong Zhang*, Hui Yang \\ School of Environment and Energy Engineering, Beijing University of Civil Engineering and Arch., Beijing, 100044, China
}

\begin{abstract}
This article discussed the lifetime of catalyst on cost effect for catalytic combustion furnace and applications of pottery heated by catalytic combustion furnace in purification water. The time of start-up process rises with the increase of the number of ignition. The catalyst sintering was remarkable. By reducing the number of ignition and adjusting the temperature rise uniformly in the furnace, the efficient utilization of thermal energy could be realized to saving production cost and extending the lifetime of catalyst. With exquisite and even-textured surface the pottery had striking purification effect on water. The water purification material of this pottery was applied to the sedimentation tank, which had remarkable water purification efficiency and could save the operating cost of the water treatment system.
\end{abstract}

Keywords: Catalytic combustion furnace; Catalyst; Lifetime; Radiation efficiency; Pottery; water purification materials.

\section{INTRODUCTION}

Catalytic combustion technique has received extensive attention all along, and it has the following advantages: completed combustion of fuel, increased combustion efficiency and low combustion temperature, which has replaced the traditional combustion device. (Kirillov et al., 2003). Catalytic combustion inhibited the extent of gas oxidation and increased the surface temperature of homogeneous ignition while preserving near zero pollutant emissions in catalytic combustion furnace (Zhang et al., 2010). Precious metals (Pt, Pd and/or Rh) are used as active components in catalyst of catalytic combustion furnace of natural gas. The results of activity measurement indicated that the noble metal particles had significant fluidity at low temperature, and the activity of the particles decreased at elevated temperature (Mari Honkanen et al., 2017).

The catalyst as a carrier for the combustion process, allowing low temperature combustion, as well as lower activation energy and selective reaction routes, to accelerate the rate of chemical reactions (Law, C. K et al., 1982). The lifetime of the catalyst affects the operating cost of the furnace directly. Due to chemical and physical factors, precious metals are sintered or shed, resulting in the loss of catalytic activity. Under Pd metal dispersion, the study showed that the aging temperature and reducing gas environment significantly deteriorated the catalytic activity through the metal oxidation state effect and support interaction, while the duration of aging was proved to be correlated with the reversibility of Pd sintering (Jason A. Lupescu et al., 2018). These conclusions provided the basis for avoiding severe aging patterns and determine the frequency of active interventions to enable catalyst regeneration (Jason A. Lupescu et al., 2016). Deactivation of Pt and Pd catalysts had been studied. Support and metal sintering due to a sudden rise in temperature aggravated the deactivation of the catalyst. Poisoning of S, P and any other metals resulted in loss activity of the catalyst (A.K. Neyestanaki et al., 2004).
In the process of urban construction, natural water body was seriously damaged and the water surface rate generally decreased, which brought heavy burden to the natural environment. China's water pollution has drawn extensive attention from diverse perspectives (Xin Miao et al., 2015). China has been facing a growing water shortage problem, which seriously threatens China's social and economic development and its sustainability. Five key aspects of water sustainability are critical, including water availability, water use patterns, waste water generation and pollution control, water institutions and management, the health of water systems and the vulnerability of society (YongJiang, 2015).

Water purification for cultivating water spinach or sweet basil by a recirculation aquaponic system was investigated either an oyster shell or ceramic ring. Some results showed that oyster shell significantly increased the $\mathrm{pH}$ and calcium in the effluent, which supports the growth of a biofilm, leading to good nitrification (Hsing Yuan Yen et al., 2016). The inorganic compounds was discussed that it had influence on the thermodynamic characteristics of the composite film, so the flow changes of hydrodynamic behavior were much lower than that of the control film of cellulose acetate (A.M. Pandele et al., 2017). The high water purification performance was mainly attributed to the high photocatalytic activity of dioxide nano fiber system structure and its porous functional layer, which was conducive to rapid infiltration (Hongwei Bai et al., 2015). Recently, the concept of sponge city is introduced into the urban promotion model. Urban drainage and rainwater management are combined with rainwater maintenance and sustainable utilization, which is compatible with urban development and solves water and environmental problems at the same time (Yong Jianga et al., 2018). The influence of catalyst lifetime on the cost of catalytic combustion furnace and the application of pottery water material in water treatment were analyzed in this paper. 


\section{EXPERIMENTAL SET-UP}

For Pd metal based honeycomb monoliths burner I, the lifetime of catalyst and its affecting factors were analyzed according to the local surface temperature, natural gas flow rate, catalyst poisoning and ignition number of times. Fig.1a illustrates catalytic combustion burner I with a photograph of catalytic combustion shown in Fig.1b. The monolith studied was $100 \mathrm{~mm}$ in diameter and $100 \mathrm{~mm}$ in length. The reactant gas feeds of natural gas and air were regulated via gas flow meter and air flow meter respectively. Fun was used to supply air for the system.

In the process of ignition, we need to sweep the inside of burner I by air for five minutes to ensure that there was no residual natural gas. The burner must be ignited by gas phase combustion with the excessive air coefficient at 1.3 during the period of start-up process. The blue flame was achieved above the monolith and gradually disappeared when the catalyst started glowing red internally as the temperatures inside the monolith increased. Then the excessive air coefficient should be adjusted to 2.0 under fuel lean condition while the catalyst reached steady state.

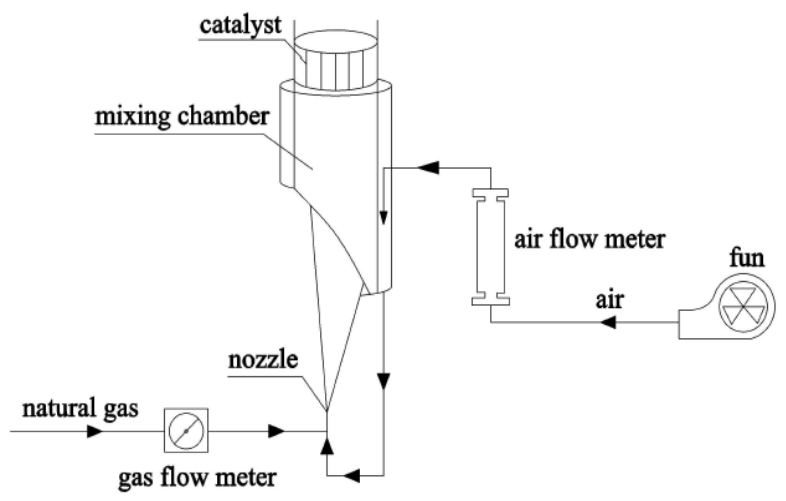

Fig. 1a Schematic diagram of catalytic combustion burner I

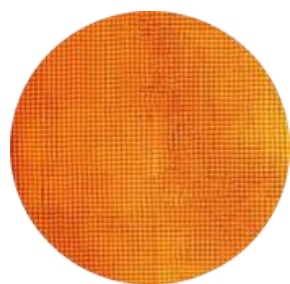

Fig. 1b Photograph of catalytic combustion

The system diagram of catalytic combustion furnace was shown in Fig. 2a. The furnace body had the shape of a cuboid. It was connected to a practical burner in $\mathrm{Pd}$ and $\mathrm{Rh}$ metals based honeycomb monolith. The support for all the monoliths tested here was cordierite. Fig.2b gives a stereogram of blank monolith and catalytic monolith. The two square catalytic honeycomb monoliths were installed in the burner each time. The square honeycomb monoliths were $150 \mathrm{~mm}$ wide and $20 \mathrm{~mm}$ long, with square-shaped cells which sectional area was $1 \mathrm{~mm} \times 1 \mathrm{~mm}$. In order to decrease the temperature of mixtures in chamber connected with the monolith entrance, the $20 \mathrm{~mm}$ long blank monoliths were inserted between the chamber and the catalytic monolith entrance as assembly of monolith. The reactant gas feeds of natural gas and air were regulated via GMS0050BSRN200000 natural gas meter and CMG400A080100000 air meter respectively. The pollutant emissions were measured by the $\mathrm{NO}-\mathrm{NO}_{2}-\mathrm{NOx}$ thermo electron analyser, $\mathrm{CO} / \mathrm{CO}_{2}$ thermo electron analyser. Exhaust gas temperature inside furnace body could be measured by thermocouple $\mathrm{K}$ of diameter 1 .

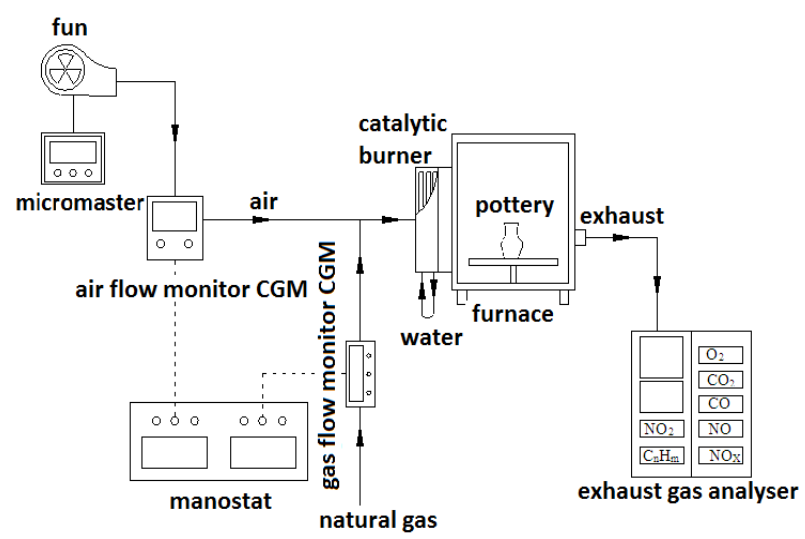

Fig. 2a System diagram of catalytic combustion furnace

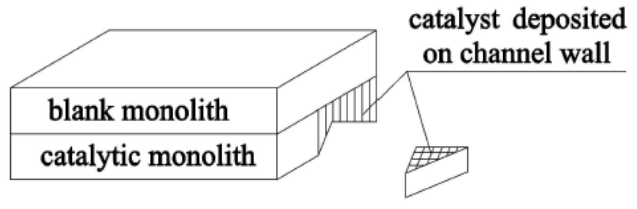

Fig. 2b Stereogram of blank monolith and catalytic monolith

\section{EXPERIMENTAL RESULT AND DISCUSSION}

\subsection{The lifetime of catalyst for burner I}

The catalytic combustion technology obtains the results of energy saving and environmental protection, but it needs time for its industrialization because the key problem still exists, such as the lifetime of catalysts. Through analyzing the affecting factors of catalyst aging, the working conditions of catalytic combustion burner can be improved in future, and its lifetime will be increased. According to experimental analyses on the lifetime of catalyst and characteristics of catalytic combustion burner I the valuable data were obtained. To some extent, it will promote the catalytic combustion burner for industrialization.

Regulation process of lifetime experiments was listed in table 1. During the period of 1823 hours of catalytic combustion ignitions were carried out seven times. The nature gas flow rates were inputted for 4.2 and $3.8 \mathrm{~L} / \mathrm{min}$.

Table 1 Relationship between the start-up process with the passage of time and lifetime of catalyst

\begin{tabular}{lrrrrrrr}
\hline $\begin{array}{l}n / \text { Number of } \\
\text { ignition }\end{array}$ & 1 & 2 & 3 & 4 & 5 & 6 & 7 \\
$\begin{array}{l}\tau / \text { Combustion } \\
\text { time } / \mathrm{h}\end{array}$ & 0 & 353 & 473 & 712 & 918 & 1332 & 1753 \\
$V /$ Natural & & & & & & & \\
$\begin{array}{l}\text { gas flow } \\
\text { rate/(L/min) }\end{array}$ & 4.2 & 4.2 & 3.8 & 3.8 & 3.8 & 3.8 & 3.8 \\
\hline
\end{tabular}

From beginning of ignition to stable catalytic combustion is called the time of start-up process. It was listed in table 1. With the increase of combustion time, the time of start-up process increased. It was indicated that aging trend appeared and activity lose gradually after repeated use of the catalyst for many times. However, a steady state was sure to be reached under fuel lean condition for catalytic combustion burner I. 


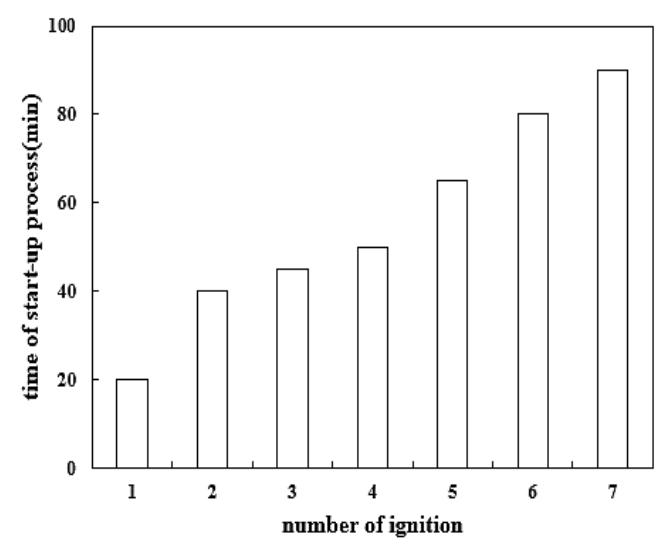

Fig. 3 The change rules for time of start-up process

The change rules of time of start-up process in the lifetime experiment of catalyst was shown in Fig. 3. The time difference between the second and first start-up process was large, while that of the other adjacent start-up process was relatively small. This meant that combustion with new catalyst could reached a steady state easily, and catalyst aging extended the region of homogeneous combustion.

\subsection{Scanning electron microscope analysis of catalysts}

The monoliths contained some loadings of precious metals ( $\mathrm{Pd}$ and $\mathrm{Rh}$ ), deposited on channel wall of washcoat supported on a cordierite honeycomb structure. There are many mechanisms of catalytic deactivation in combustion application, which are divided into six intrinsic deactivation mechanisms. Each of them was described briefly in table 2 (Bartholomew, 2001).

Table 2 Mechanisms of catalytic deactivation

\begin{tabular}{|c|c|c|}
\hline Mechanisms & Type & Brief definition / description \\
\hline Poisoning & Chemical & $\begin{array}{l}\text { Strong chemisorption of species on } \\
\text { catalytic sites, thereby blocking sites } \\
\text { for catalytic reaction. }\end{array}$ \\
\hline Fouling & Physical & $\begin{array}{l}\text { Physical deposition of species from } \\
\text { fluid phase onto the catalytic surface } \\
\text { and catalyst pores. }\end{array}$ \\
\hline $\begin{array}{l}\text { Thermal } \\
\text { degradation }\end{array}$ & Thermal & $\begin{array}{l}\text { Thermally induced loss of catalytic } \\
\text { surface area, support area, and active } \\
\text { phase-support reactions. }\end{array}$ \\
\hline $\begin{array}{l}\text { Vapour } \\
\text { formation }\end{array}$ & Chemical & $\begin{array}{l}\text { Reaction of gas with catalyst phase to } \\
\text { produce volatile compounds. }\end{array}$ \\
\hline $\begin{array}{l}\text { Vapour-solid } \\
\text { and solid } \\
\text { reactions }\end{array}$ & Chemical & $\begin{array}{l}\text { Reaction of fluid, support, or promoter } \\
\text { with catalytic phase to produce } \\
\text { inactive phase. }\end{array}$ \\
\hline Attrition & Physical & $\begin{array}{l}\text { Loss of catalytic material due to } \\
\text { abrasion. }\end{array}$ \\
\hline
\end{tabular}

The main composition of natural gas is methane. In order to help its users detect gas leaks easily, sulphur is added in the distribution network as a mixture of $\mathrm{H}_{2} \mathrm{~S}$ with a strong odour. No effects of adding the sulphur compounds were observed on the monolith temperatures and emissions. Sintering or thermal deactivation is the main reason for activation lose gradually.
Microscopic views of new and ageing catalysts by Scanning Electron Microscope (SEM) are shows in Fig. 4. It is clearly observed that the active components of new catalysts were neat and distributed orderly on the channel wall with uniform particle size. However the active components of the aging catalyst were disordered. The size of the particle became scattered and bulk sintering occurred. In particular, sintered part increased obviously and reduced activation of catalytic honeycomb monoliths.

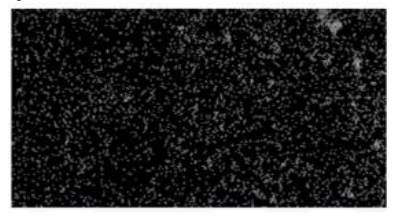

a

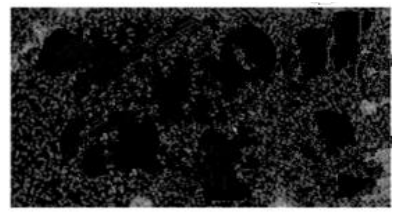

$\mathrm{b}$
Fig. 4 Microscopic views of channel wall inside catalytic honeycomb monoliths for furnace
(a) New
(b) Used

The extensive sintering of the catalyst has so far slowed down the widespread use of catalytic combustion. This will drive to motivate research increasingly and be oriented to the development of cheaper, regenerative and durable catalytic materials.

\subsection{The lifetime of catalyst on cost effect for catalytic combustion furnace}

In an enclosed furnace radiation heat exchange between the surface of catalytic honeycomb monoliths and the wall surface was regarded as the radiation heat exchange between two gray bodies in an enclosed cavity. It was calculated by Eq. (1):

$$
\phi_{1,2}=\frac{A_{1} \sigma\left(T_{1}^{4}-T_{2}^{4}\right)}{\left(\frac{1}{\varepsilon_{1}}-1\right)+\frac{1}{X_{1,2}}+\frac{A_{1}}{A_{2}}\left(\frac{1}{\varepsilon_{2}}-1\right)}
$$

Where $\varepsilon_{1}$ is the emissivity of catalytic honeycomb monoliths surface, which was 0.5 . Its radiation outputs were calculated based on the surface temperatures measured by the infrared pyrometer and using an effective emissivity $\varepsilon_{1}$ of 0.5 . The wall surface is surrounded by heat sink. As the material of wall surface was made up of refractory cotton soil, the emissivity $\varepsilon_{2}$ was $0.85 . X_{1,2}$ is the shape factors, here was $1, A_{l}$ is the apparent area of the monolith at the open end, which was $A_{1}=0.15 \times 0.3=0.045 \mathrm{~m}^{2}$. The inner casing of furnace still had the shape of a cuboid, whose edges were $370 \mathrm{~mm}$ long, $150 \mathrm{~mm}$ wide and $300 \mathrm{~mm}$ high. $A_{2}$ is the apparent area of the wall surface, which was $A_{2}=0.378 \mathrm{~m}^{2} . T_{1}$ is the average surface temperature of monoliths for heating pottery, which was $1323 \mathrm{~K}$. $T_{2}$ is the average temperature of the wall surface, which was recorded approximately as $1113 \mathrm{~K}$ by thermocouple K. Pottery was heated about $840{ }^{\circ} \mathrm{C}$ in the catalytic combustion furnace.

The catalytic combustion furnace of natural gas possesses high radiation heat transfer characteristics with environmentally friendly and energy-saving. This high radiant heat exchange inside furnace had a key role to heating pottery.

In order to be conducive to the full use of heat energy, it was importance to reduce the number of ignition, and control the temperature rise uniformly in the furnace. When the service life of catalyst was prolonged the saving production cost and high efficiency of the furnace could be obtained. The coordinated development between industrial production and economic benefit of furnace is achieved. Pottery materials heated by catalytic combustion furnace was shown in Fig. 5. 

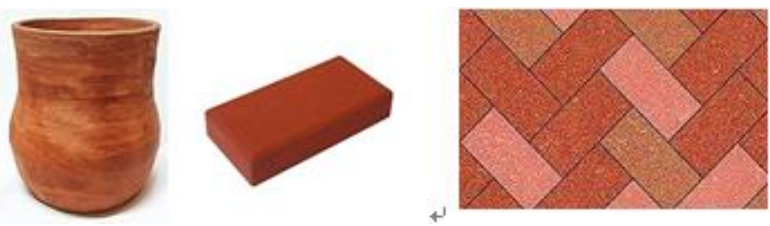

Fig. 5 Pottery materials heated by catalytic combustion furnace

\subsection{Purification of pottery to water}

Pottery was used as the experimental group and the porcelain was used as the control group. The water samples were taken from a river in Beijing. The water sample staying for 4 days in the pottery container and the original water sample were shown in Fig. 6a,b. It was observed that the suspended particles of water samples in the pottery almost disappeared, and the water quality became clean and transparent.

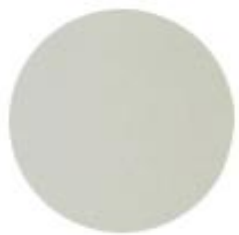

a

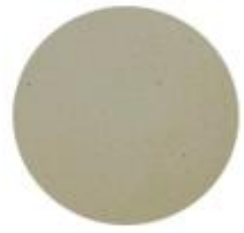

b
Fig. 6 The comparison diagram of water sample (a) Water sample in the pottery container for four days (b) Original water sample from a river

The curves of turbidity of water samples for two days and four days in two containers were shown respectively in Fig. 7a.b. The turbidity of the original water samples was 7.0 NTU through testing. The turbidity of water sample in pottery container dropped obviously from 7.0 NTU to about 2.0 NTU. It remained basically stable in the last. However the turbidity of the water sample in porcelain container decreased in a small range and its turbidity was around 6.5NTU. Fig. 7c plots turbidity of water sample in pottery container for three days. The turbidity of water sample in the concrete container was also investigated. It could decrease the turbidity of water around 4 NTU (not shown here).

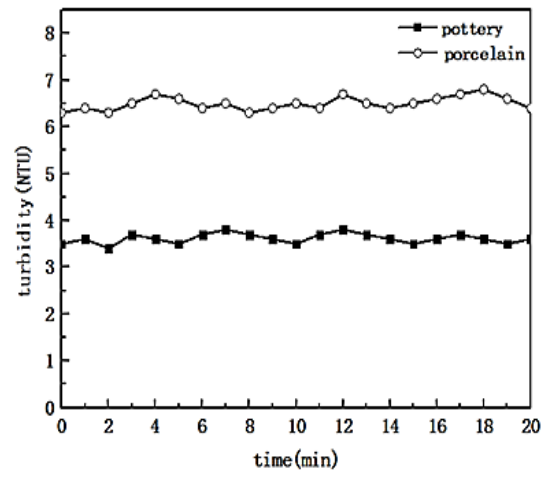

a

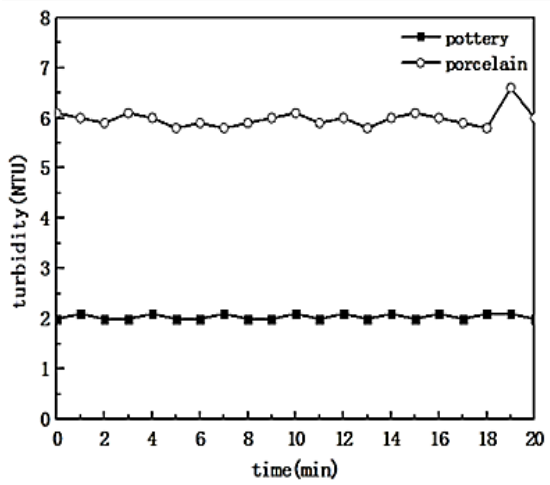

b

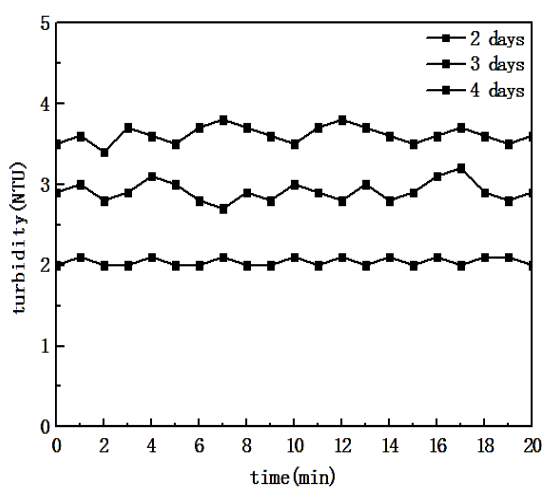

c

Fig. 7 Curves of turbidity of water samples

Pottery could filter river water effectively. Thus removal of insoluble substances from water is realized. The indication error for turbidity of turbidimeter was usually $\pm 0.4 \mathrm{NTU}$. The data analyzed by variance theory were found to be in a reasonable range.

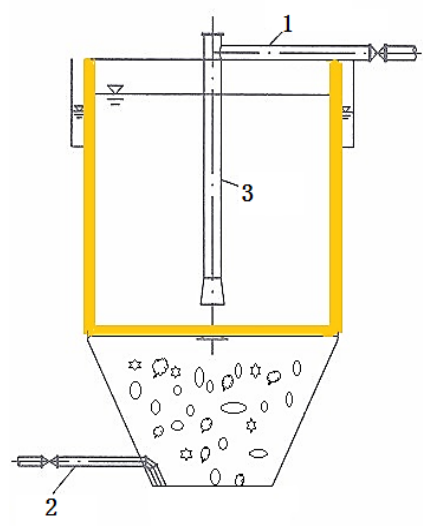

1- Water inlet 2-Submerged discharge pipeline 3-Central pipe

Fig. 8 sedimentation tank in the water treatment system

The sedimentation tank in the water treatment system was shown in Fig. 8. It is a kind of purifying water equipment for removing suspended matter in water by precipitation.

The catalytic combustion of natural gas furnace could meet the requirement for heating pottery. The surface of the pottery is exquisite and even-textured and a pastoral atmosphere lingers around. When water purification materials of this pottery could be built in the whole pool bottom and surrounding of the tank as purification water wall it is significant to increase the contact area between the materials and water. Then, the precipitation rate could be speeded up as well as achieving the preliminary water purification.

\section{CONCLUSIONS}

It was indicated that the time of start-up process rise when the number of ignition increase for catalytic combustion. In order to effective operation of the furnace system the number of ignition should be reduced and the temperature was controlled uniformly. It need avoid loss of catalytic material due to abrasion to extend the lifetime of the catalyst.

The core technology of catalytic combustion furnace with natural gas as heat source is fully premixed combustion in appropriate proportion. The main basic way of heat transfer inside the catalytic combustion furnaces is thermal radiation. The larger apparent area of the monolith in the furnace could improve the radiation efficiency. The depth study of catalytic monolith can reduce cost and enhance feasibility of the catalytic combustion furnace in actual production.

It was concluded that the effect of purification water is remarkable 
of pottery according to turbidity analysis. This pottery could be used as the preliminary water purification wall in the sedimentation tank in the traditional water purification system. It increased the contact area between water samples and purification materials, improved the precipitation rate to save cost for the whole water treatment system.

\section{ACKNOWLEDGMENT}

The project was sponsored by The Fundamental Research Funds for Beijing Universities of Civil Engineering and Architecture, Beijing Scholar Program and Beijing Future Urban Design High-Tech Innovation Center.

\section{NOMENCLATURE}

$A_{l} \quad$ apparent area of the monolith at the open end $\left(\mathrm{m}^{2}\right)$

$A_{2} \quad$ apparent area of the wall surface $\left(\mathrm{m}^{2}\right)$

$n$ number of ignition

$T_{1} \quad$ average surface temperature of monoliths (K)

$T_{2} \quad$ average temperature of the wall surface $(\mathrm{K})$

$V \quad$ natural gas flow rate in burner $\mathrm{I}(\mathrm{L} / \mathrm{min})$

$X_{1,2} \quad$ shape factors

Greek Symbols

$\tau \quad$ combustion time(h)

$\Phi_{1,2} \quad$ radiation heat exchange $(\mathrm{kW})$

$\varepsilon_{1} \quad$ emissivity of catalytic honeycomb monoliths surface

$\varepsilon_{2} \quad$ emissivity of wall surface

$\sigma \quad$ Stephan-Boltzmann constant

\section{REFERENCES}

A.K. Neyestanaki, F. Klingstedt, T. Salmi, D.Y. Murzin., 2004, "Deactivation of post combustion catalysts, a review". Fuel, 83(4-5), 395-408.

https://doi.org/10.1016/j.fuel.2003.09.002

A.M. Pandele , F.E. Comanici, C.A. Carp , F. Miculescu, S.I. Voicu, V.K. Thakur, B.C. Serban., 2017, "Synthesis and characterization of cellulose acetate-hydroxyapatite micro and nano composites membranes for water purification and biomedical applications". Vacuum, 146,599-605.

http://dx.doi.org/10.1016/j.vacuum.2017.05.008

Bartholomew C H. 2001.Mechanisms of catalytic deactivation. Applied Catalysis A: General, 212 (1-2), 17-60.

https://doi.org/10.1016/S0926-860X(00)00843-7

Hongwei Bai, Xiaoli Zan, Jermyn Juay, Darren Delai Sun., 2015, "Hierarchical heteroarchitectures functionalized membrane for high efficient water purification". Journal of Membrane Science, 475,245251.

http://dx.doi.org/10.1016/j.memsci.2014.10.036
Hsing Yuan Yen, Jung Hua Chou., 2016, "Water purification by oyster shell bio-medium in a recirculating aquaponic system". Ecological Engineering, 95, 229-236.

https://doi.org/10.1016/j.ecoleng.2016.06.065

Jason A.Lupescu, Johannes W.Schwank, Galen B.Fisher, JonHangs, Sabrina L.Peczonczyk, William A.Paxton., 2018, "Pd model catalysts: Effect of air pulse length during redox aging on Pd redispersion", Applied Catalysis B: Environmental, 223, 76-90.

https://doi.org/10.1016/j.apcatb.2017.07.055

Jason A.Lupescu,Johannes W.Schwank,Galen B.Fisher, XiaoyinChen, Sabrina L.Peczonczyk, Andy R.Drews., 2016, "Pd model catalysts: Effect of aging duration on lean redispersion". Applied Catalysis B: Environmental, 185, 189-202.

https://doi.org/10.1016/j.apcatb.2015.12.012

Kirillov, V. A., Kuzin, N. A., Kulikov, A. V., Fadeev, S. I., Shigarov, A. B., and Sobyanin, V. A., 2003, "Thermally Coupled Catalytic Reactor for Steam Reforming of Methane and Liquid Hydrocarbons: Experiment and Mathematical Modeling". Theoretical Foundations of Chemical Engineering, 37(3), 276-284.

http://dx.doi.org/10.1023/A:1024039823317

Law, C. K., and Sivashinsky, G. I., 1982, "Catalytic Extension of Extinction Limits of Stretched Premixed Flames". Combustion science and Technology, 29(3-6), 277-286. https://doi.org/10.1080/00102208208923602

Mari Honkanen, Thomas W. Hansen, Hua Jiang, Marja Kärkkäinen, Mika Huuhtanen, Olli Heikkinen, Kauko Kallinen, Jouko Lahtinen, Riitta L. Keiski, Jakob B. Wagner, Minnamari Vippola, 2017, "Electron microscopic studies of natural gas oxidation catalyst - Effects of thermally accelerated aging on catalyst microstructure". Journal of Catalysis, 349, 19-29.

https://doi.org/10.1016/j.jcat.2017.03.003

Xin Miao a, Yanhong Tang, Christina W.Y. Wong, Hongyu Zang, 2015, "The latent causal chain of industrial water pollution in China". Environmental Pollution, 196,473-477. https://doi.org/10.1016/i.envpol.2014.11.010

YongJiang., 2015, "China's water security: Current status, emerging challenges and future prospects". Environmental Science \& Policy, 54,106-125.

https://doi.org/10.1016/j.envsci.2015.06.006

Yong Jianga, Chris Zevenbergena, Yongchi Mab., 2018, "Urban pluvial flooding and stormwater management: A contemporary review of China's challenges and "sponge cities" strategy". Environmental Science and Policy, 80,132-143.

https://doi.org/10.1016/j.envsci.2017.11.016

Zhang, S. and Li, N., 2010, "Research on Mechanisms and Applications of Catalytic Combustion of Natural Gas". Frontiers in Heat \& Mass Transfer, 2(3), 1-6.

http://dx.doi.org/10.1115/IHTC14-220 